\title{
COVID-19 lockdown improves air quality in Morocco
}

\author{
Imane SEKMOUDI ${ }^{{ }^{\dagger}}$, Laila IDRISSI ${ }^{1}$, Kenza KHOMSI ${ }^{2}$, Soufiane FAIEQ ${ }^{3,4}$, Mohamed EL JARMOUNI ${ }^{5}$, \\ Meryem TANARHTE ${ }^{1}$ \\ ${ }^{1}$ Hassan II University of Casablanca, Faculty of Sciences and Techniques of Mohammedia (FSTM), Laboratory of Process Engineering and \\ Environment, 20650 Mohammedia, Morocco \\ ${ }^{2}$ General Directorate of Meteorology, Face préfecture Hay Hassani, B.P. 8106 Casa-Oasis, Casablanca, Morocco \\ ${ }^{3}$ Univ.Grenoble Alpes, CNRS,Grenoble INP( Institute of Engineering Univ.Grenoble Alpes), Grenoble, France \\ ${ }^{4}$ LRIT Associated Unit to CNRST (URAC 29), Faculty of Sciences, Mohammed V University in Rabat, Rabat, Morocco \\ ${ }^{5}$ Abdelmalek Essaadi University, National School of Applied Sciences, Water and Environmental Engineering Team, Applied Sciences Laboratory, \\ B.P03, Ajdir, Al-Hoceima, Morocco
}

\section{ABSTRACT}

Several measures have been taken to mitigate the effects of the COVID-19 pandemic. In this context, almost all non-essential activities in Morocco have been halted since March 20, 2020. From that date, Morocco announced the lockdown for one month and it was extended until June 10, 2020. The main objective of this paper is to study the effects of the lockdown measures on air quality, by analyzing dust $\mathrm{PM}_{2.5}, \mathrm{NO}_{2}$, and $\mathrm{O}_{3}$. The dust $\mathrm{PM}_{2.5}$ analysis was carried out from 2016 to $2020 . \mathrm{NO}_{2}$ and $\mathrm{O}_{3}$ analysis was carried out in 2019 and 2020. This study, which is based on satellite data from TROPOMI Sentinel 5P and MERRA, has shown that Morocco has experienced an improvement in air quality during the lockdown. A significant reduction in surface dust $\mathrm{PM}_{2.5}$ and tropospheric $\mathrm{NO}_{2}$ was observed $(-10 \%,-4 \%$, respectively on average). The total column of ozone recorded a slight increase on average of around $1 \%$. Moreover, we demonstrate that a significant part of particulate pollution and $\mathrm{NO}_{2}$ emissions are incoming mainly from the northern and northern-eastern borders of Morocco.

Keywords: Air quality, COVID-19 lockdown, Dust $\mathrm{PM}_{2.5}$, Morocco, $\mathrm{NO}_{2}, \mathrm{O}_{3}$

\section{Introduction}

The new SARS-CoV-2 coronavirus (COVID-19) was first discovered in China at its epicenter Wuhan. On August 31, 2020, COVID-19 has led to more than 25,172,255 confirmed cases and 846,542 deaths worldwide [1]. Since the declaration of the COVID-19 epidemic as a public health emergency of international concern, several countries have adopted certain restricting policies such as the implementation of social distancing and quarantine measures [2].

On March 02, 2020, Morocco announced the first confirmed case of COVID-19. Since then, the Moroccan authorities have taken several measures and proactive decisions. On March 11, 2020, Morocco created an Economic Vigilance Committee and then informed the public about the preventive measures to limit the spread of the virus. The "state of health emergency", which is an exceptional measure that can be decided by the Council of Ministers in the event of a health disaster, was announced and then it was extended several times [3]. This allows undertaking a battery of exceptional measures of social, economic, or political order such as the closure of the borders and the restriction of the circulation [4]. The lockdown is a technical-administrative measure that prohibits the displacement of any person out of its residents except for displacements of an urgent nature [4]. The lockdown is part of measures dictated in the "state of health emergency". Morocco has been on lockdown from March 20, 2020, until June 10, 2020. On August 31, 2020, COVID-19 has led to more than 61.399 confirmed cases and 1.111 deaths for the entire kingdom of Morocco [1].

Since 1997, Morocco has started to strengthen its legal and institutional arsenal relating to air quality. The elaboration of law 13-03, decrees, orders, and programs on air pollution, all reflect the effort of the country in that context. Also, Morocco has elaborated reports on the environment state and has realized many cadastres of atmospheric emissions [5-10]. Morocco currently has a national air quality monitoring network consisting of 5 mobile and 29 fixed measure-
This is an Open Access article distributed under the terms of the Creative Commons Attribution Non-Commercial License (http://creativecommons.org/licenses/by-nc/3.0/) which permits unrestricted non-commercial use, distribution, and reproduction in any medium, provided the original work is properly cited.

Copyright (C) 2022 Korean Society of Environmental Engineers
Received April 22, 2021 Accepted October 02, 2021

${ }^{\dagger}$ Corresponding author

E-mail: imane.sekmoudi@gmail.com

Tel: +212638-90-78-09 Fax: +212523315353

ORCID: 0000-0003-0803-3440 
ment stations covering 15 cities in the Kingdom. Nitrogen dioxide, ozone, and particulate matter with a diameter less than $10 \mu \mathrm{m}$ are the main air pollutants monitored in Morocco. These pollutants, which are important indicators of economic and human activities, are among the air quality indicator pollutants according to the Moroccan standards [11].

The main objective of the present paper is to study the effects of the COVID-19 lockdown on air quality by analyzing dust surface mass concentration of $\mathrm{PM}_{2.5}$ (particulate matter less than $2.5 \mathrm{mi}$ crons), tropospheric vertical column of $\mathrm{NO}_{2}$, and total $\mathrm{O}_{3}$ column pollutants as indicators of air quality.

This paper is structured as follows. Section 2 presents the international and national experiences of the effect of the COVID-19 lockdown on air pollution. Section 3 describes the used data, the periods, and the study area. In section 4 , we present the results of the study. Then in the last section, we present the conclusion and the author's recommendations.

\section{COVID-19 Lockdown Effect on Air Pollution}

At the international level, several studies have reported a reduction in air pollution thanks to the reduction in traffic and industrial activities during the COVID-19 lockdown. In China, Wuhan [12] and 44 cities in the country [13], an improvement in the air quality index was recorded. Similar results have been reported in Italy, France, Spain, Germany, Bangladesh, and the USA [14-21]. This was also observed in the most polluted cities in the world, notably Bangalore, Beijing, Bangkok, Delhi, and Nanjing, as well as in the main shopping centers of the world, notably New York, London, Paris, Seoul, Sydney, and Tokyo [22].

Likewise in China, a study showed that the shutting down of industrial and anthropogenic activities caused by COVID-19 may have saved more lives by preventing air pollution than by preventing infection [12]. Moreover, another study found that high levels of air pollution may favor the spread of the SARS-CoV-2 infection [23]. In the same context, a study conducted in 66 administrative regions in Italy, Spain, France, and Germany indicates that long-term exposure to $\mathrm{NO}_{2}$ may be one of the most important contributors to the mortality caused by the COVID-19 virus [24]. This study estimates that this cause is maybe worldwide. Also, in the US, an increase of $1 \mu \mathrm{g} / \mathrm{m}^{3}$ in $\mathrm{PM}_{2.5}$ was associated with a $15 \%$ increase in mortality from COVID-19 [25]. Furthermore, two studies conducted in India and Milan metropolitan area (Lombardy region) have shown a positive correlation between PM levels and the COVID-19 pandemic, suggesting that these pollutants could lead to the spreading of the virus [26, 27].

Since the declaration of the COVID-19 epidemic as a Public health emergency of international concern by the World Health Organization (WHO) [28], several countries have implemented flight restrictions and preventive measures [2]. Morocco took the initiative to monitor and quarantine citizens from countries affected by COVID-19 and then suspended the majority of industrial and commercial activities. Also, the transportation and movement of citizens were limited only to necessary needs of work, medical needs or groceries, or other compulsory necessities. In the same way, all social activities that result in mass gathering such as ceremonies, educational establishments, religious festivals, sports competitions were prohibited [29].

A study conducted in Casablanca and Marrakech cities shows that the air pollution reduction in the lockdown period had created human health benefits. Furthermore, it reduced mortality and saved lives mainly from cardiovascular diseases (more than $60 \%$ of the avoidable deaths). The study estimates that reduction in $\mathrm{NO}_{2}$ during the quarantine period avoided $185 \mathrm{NO}_{2}$ related deaths in Casablanca and 30 in Marrakech. $\mathrm{PM}_{2.5}$ reduction avoided 48 related deaths in Casablanca and 15 in Marrakech. Additionally, it is showed that $\mathrm{NO}_{2}$ dropped by -12 and $-7 \mu \mathrm{g} / \mathrm{m}^{3}$, while $\mathrm{PM}_{2.5}$ dropped by -18 and $-14 \mu \mathrm{g} / \mathrm{m}^{3}$ and CO decreased by -0.04 and $-0.12 \mathrm{mg} / \mathrm{m}^{3}$, respectively in Casablanca and Marrakech cities [30].

In Sale city, a study showed that $\mathrm{PM}_{10}, \mathrm{SO}_{2}$, and $\mathrm{NO}_{2}$ concentrations were reduced by more than a half during the COVID-19 lockdown. The reduction of these concentrations during the lockdown was respectively 75,49 , and $96 \%$. The authors concluded that this reduction can be mainly attributed to drastic measures limiting human movement and industrial activities [31]. Moreover, another study conducted in Morocco's capital, Rabat, highlights the effectiveness of limited emissions on air quality. This study showed drastic reductions in $\mathrm{NO}$ (up to $94 \%$ ), $\mathrm{NO}_{2}$ (up to $51 \%$ ), $\mathrm{PM}_{2.5}$ (up to $45 \%$ ), $\mathrm{PM}_{10}$ (up to $53 \%$ ) and an increase of approximately $20 \%$ in $\mathrm{O}_{3}$ mean concentrations [32].

In China, a study has shown that serious episodes of air pollution are not avoided by reducing activities (traffic and industrial activities) during COVID-19, especially when the weather is unfavorable [33]. Also, other studies have shown the increase of secondary pollutants such as $\mathrm{O}_{3}$ in some cities in Europe, China, and India even with strict measures to control primary pollutants emissions [34, 35].

We argue that the sustainability of the benefits of reducing air pollution due to the COVID-19 should be investigated by looking at the situation after the crisis of this pandemic [12].

\section{Data and Methods}

\subsection{The Study Area}

Morocco is a northern African country located on the border between Europe and Africa and between the Mediterranean and the Atlantic. It is located at the northwestern tip of Africa. The Moroccan territory has a wide variety of climates. The climate is Sahara desert, arid or semi-arid in the south and east of the country (more than $90 \%$ of the Moroccan territory), and more humid climates of sub-humid or humid climates in the northeast of the country [10].

Morocco is characterized by a high sensitivity to climate change and its limited adaptation capacities [36]. It is considered among the most vulnerable countries to climate variability and transboundary air pollution [37]. In these recent decades, it is characterized by a tendency to rise in temperatures [38].

In 2020, Morocco recorded a population of more than 36,094,351 [39]. Because of the COVID-19 pandemic, On August 31, 2020, Morocco recorded 1,111 deaths and 61,399 confirmed cases [1].

The choice of Morocco as a study area is based on one hand on its ranking as the $31^{\text {st }}$ country in the world in terms of the 
total cumulative number of confirmed cases (On November 21, 2020) [1]. On the other hand, Morocco is a model country in the management of the health crisis due to COVID-19 as it is among the first countries in Africa and the MENA (the Middle East and North Africa) region in terms of response to this crisis. Moreover, the objective of this paper is to study the effects of the COVID-19 lockdown measures on air quality.

\subsection{The Study Period}

For dust surface mass concentration of $\mathrm{PM}_{2.5}$, we have chosen the study period going from 2016 to 2020 . However, depending on the availability of TROPOMI Sentinel 5P data, the study period of the tropospheric vertical column of $\mathrm{NO}_{2}$ and total $\mathrm{O}_{3}$ column is 2019 and 2020.

These variables are analyzed over three periods during the years of the study mentioned above. The first period corresponds to the period before the lockdown (P1). It covers the dates between January 01 and March 19. The period between March 20 and June 10 corresponds to the lockdown period (P2) and the period between June 11 and August 31 reflects the period after the lockdown (P3).

\subsection{Air Quality and Meteorological Data}

This study focuses on road traffic pollutants as the lockdown in Morocco was strict with prohibiting citizen's mobility. In the country, the main traffic pollutants are $\mathrm{PM}$ and $\mathrm{NO}_{2}$. MERRA offers $\mathrm{PM}_{2.5}$ data and Sentinel $5 \mathrm{P}$ offers $\mathrm{NO}_{2}$ data. The choice of these two pollutants is based on their importance in air quality assessment and on its environmental and health impacts. A study indicates that long-term exposure to $\mathrm{PM}_{2.5}$ may be one of the most important contributors to deaths exacerbated by the COVID-19 virus and possibly worldwide [40]. Also, PM can be one of the driving factors of COVID-19 transmission in the air [41].

$\mathrm{NO}_{2}$ is an important precursor of air pollution in the atmosphere. Also, it has been shown that reducing this pollutant internationally and nationally during the COVID-19 lockdown period has benefits for human health [17, 30, 42].

Total $\mathrm{O}_{3}$ column was chosen as a secondary pollutant to see its variation in all levels of the atmosphere and because it's monitoring is taken into account by Moroccan regulations. Moreover, it is an indicator of $\mathrm{NO}_{2}$ chemical transformation.

Also these pollutants were chosen for their relationship with the COVID-19 lockdown scenario and the positive health effects noticed in several countries following their reduction during the lockdown period [24, 25, 34, 35].

\subsubsection{Sentinel-5 precursor tropospheric monitoring instrument (S5P/TROPOMI)}

S5P/TROPOMI is the first Copernicus mission satellite devoted to monitoring the atmosphere. It was launched on October 13, 2017 [43]. Copernicus data is issued from the European Union's Earth Observation Program. It combines satellite observations (such as sentinel 5P) and atmospheric modeling data. Copernicus Atmosphere Monitoring Service Reanalysis (CAMSRA) data are the latest global reanalysis data set of atmospheric composition produced by the CAMS (Copernicus Atmosphere Monitoring Service). A study examined CAMSRA data against the average daily PM10 concentrations collected from fixed Moroccan air quality measurement stations. This study concluded that CAMSRA data can be used for Morocco to calculate climatology, study trends, evaluate models or compare other reanalyses [44].

For this paper, the TROPOMI offline and reprocessing datasets in processing level 2 was used for two pollutants, which are the tropospheric vertical column of $\mathrm{NO}_{2}$ and the total $\mathrm{O}_{3}$ column. These satellite data with a high resolution are used to assess the Spatio-temporal evolution of these pollutants in Morocco.

\subsubsection{Modern-era retrospective analysis for research and applica- tions version 2 (MERRA-2)}

MERRA-2 provides atmospheric data dating back from 1980 to dat e. It is the first long-term global reanalysis to assimilate space-based observations of aerosols and represent their interactions with other physical processes in the climate system [45]. The MERRA-2 is a National Aeronautics and Space Administration (NASA) atmospheric reanalysis for the satellite era using the Goddard Earth Observing System Model, Version 5 (GEOS-5) with its Atmospheric Data Assimilation System (ADAS), version 5.12.4 [46].

The MERRA-2 reanalysis data used in this paper are dust surface mass concentrations of $\mathrm{PM}_{2.5}$ with a spatial resolution of $0.5 \times$ 0.625. This data is used to assess the Spatio-temporal evolution of the dust surface mass concentrations - $\mathrm{PM}_{2.5}$ in Morocco using the NASA GIOVANNI system. MERRA-2 data has been found to better simulate surface fine particulate mass $\mathrm{PM}_{2.5}$ [47]. Some studies have shown the compatibility of MERRA's data trends with ground trends, such as the study conducted in the Monterrey Metropolitan Area in Mexico [48].

\subsubsection{The ERA5 datasets}

ERA5 provides hourly estimates of a large number of atmospheric, land, and oceanic climate variables. It includes information about uncertainties for all variables at reduced spatial and temporal resolutions. The data cover the Earth on a $30 \mathrm{~km}$ grid and resolve the atmosphere using 137 levels from the surface up to $80 \mathrm{~km}$ in altitude [49].

To properly interpret the evolution of pollutants during the study period, ERA5 data was used to acquire meteorological parameters, mainly temperature, precipitation, and wind speed.

\subsection{Methods}

\subsubsection{Kriging and model builder}

The kriging method is a powerful statistical and spatial interpolation method. It uses complex mathematical formulas to estimate values at unknown points based on values at known ones [50]. The Kriging method is chosen because it is used as an interpolation statistical method in similar studies [51]. Moreover, [52] showed that the average Kriging error is lower than that of the IDW (Inverse Distance Weighting) method in their study about particulate matter.

There are several types of kriging, including universal, coKriging, median polish, indicator, and ordinary kriging. This last method, which is the basis of geostatistics, is used in this study to interpolate the three pollutants studied in the study area. We have chosen this type of kriging because it gives optimum predictions under the assumption that the process is second order stationary and 
distributed with the normal. Also, because the observed values are the realization of a stationary stochastic process of a fairly simple structure [53].

The Model Builder of ArcGIS, a visual modeling tool, is used to automatically iterate the kriging on all the shapefiles of the same chosen study period, using the spatial analysis tool of Arc Toolbox. A mask of the borders of Morocco was used to limit the processing area. This method allows us to optimize the time in the workflow process.

\subsubsection{DiD approach}

To quantify the evolution of air pollution during the lockdown period, we used the Difference in Differences (DiD) approach. It is a statistical method used to estimate the effect of a chosen treatment. It consists of comparing the difference between the control group and the treated group before and after the introduction of the treatment. $\mathrm{DiD}$ approach is a quasi-experimental research design that is often used to study causal relationships in different fields [54, 55]. Several studies have used this method to show the air pollution changes during the lockdown due to COVID-19 [56-58].

In this approach, we compared the difference in concentrations of the pollutants studied during the lockdown (P2) compared to the period before and after the lockdown (P1 and P3) in

(i) 2020, and (ii) 2016-2019 (for dust surface mass concentration of $\mathrm{PM}_{2.5}$ ) and (iii) 2019 (for the tropospheric vertical column of $\mathrm{NO}_{2}$ and total column of $\mathrm{O}_{3}$ ).

The defined periods and the significance of all the maps of the Spatio-temporal evolution, as well as that of the DiD approach, are presented in Table 1.

\section{Results and Discussion}

\subsection{Meteorological Data Analysis}

The meteorological data used in this study include average temperature $\left({ }^{\circ} \mathrm{C}\right)$, wind speed $(\mathrm{Km} / \mathrm{h})$ and precipitation level $(\mathrm{mm})$. The analysis of these data shows a similar situation for the average temperature during the three periods in 2020 and 2019 with an increasing trend for both years (see Fig. 1).

Regarding the wind speed, as shown in Fig. 1, it keeps almost the same pace in 2019 and 2020 with an increasing trend followed by a slight decrease or stagnation in the northern and central regions of Morocco. On the other hand, the regions of Dakhla-Oued Ed-Dahab and Laayoune- Sakia El Hamra record a slight downward trend followed by a small upward trend. During the second period (b Vs e), the Draa- Tafilalet region recorded a wind speed in 2020 higher than that in 2019 '+10\%'.

Finally, for precipitation, there is generally an upward trend followed by a downward trend in 2019 and 2020. The northern and central regions of Morocco record the highest rainfall. The precipitation during P1 and P3 in 2019 was higher than that of 2020. However, during the second period, the average precipitation in 2020 was slightly higher than that of 2019, which promotes leaching and also contributes to the reduction of air pollution.

\subsection{Dust Surface Mass Concentration- $\mathrm{PM}_{2.5}$}

Regarding the 2016-2019 average, Fig. 2(a)-(c) and Fig. 3 show an upward trend throughout the study period except for GuelmimOued Noun, Tangier- Tetouan- Al Hoceima, and Casablanca-Settat regions. These regions recorded a decrease between the first and the second periods in the order of $-2 \%,-6 \%$, and $-7 \%$, respectively.

In 2020, owing to the lockdown due to COVID-19, Fig. 2(d)-(f) and Fig. 3 show, on average, a downward trend followed by an upward trend. Fig. 2(C) shows a strong decrease ranging from $-59 \%$ in Laayoune-Sakia El Hamra to $-16 \%$ in Dakhla- Oued Ed-Dahab. On the other hand, six (6) regions kept an increase varying between $9 \%$ in the Marrakech- Safi region and 57\% in the Draa- Tafilalet region. After lockdown, Fig. 2(D) shows an increase of dust $\mathrm{PM}_{2.5}$ concentrations in all regions except the regions of Rabat-Sale-Kenitra and Tangier-Tetouan-Al Houceima with a small reduction of around $-1 \%$ and $-8 \%$, respectively. This increase in concentration after the lockdown may be due to the combustion of fossil fuels in vehicles due to the return of automobile traffic, also by industrial processes, and wind erosion as well as sandstorms.

During the second period, all regions recorded a decrease of dust mass concentration of $\mathrm{PM}_{2.5}(-10 \%$ on average), except the regions of Draa-Tafilalet and the Oriental which experienced a slight increase of around $2 \%$ and $16 \%$, respectively. This increase in concentration explains the natural contribution of these particles from the neighbouring areas of eastern and northern Morocco. This result supports the results of the study highlighting the predom-

Table 1. Study Period

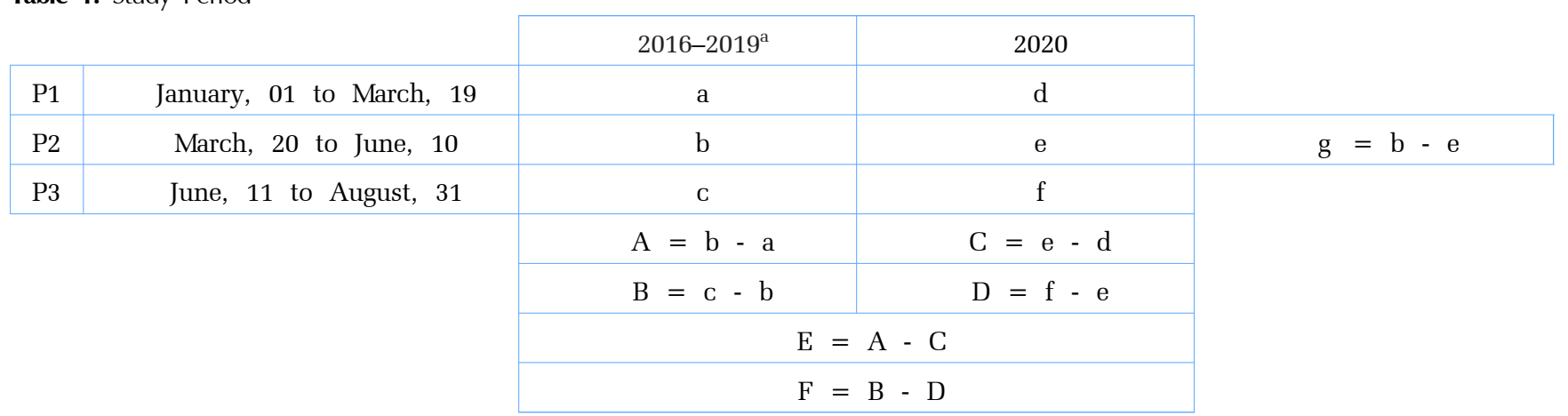

${ }^{\text {a }}$ For tropospheric vertical column of NO2 and total ozone column variables, there are only the averages of 2019 

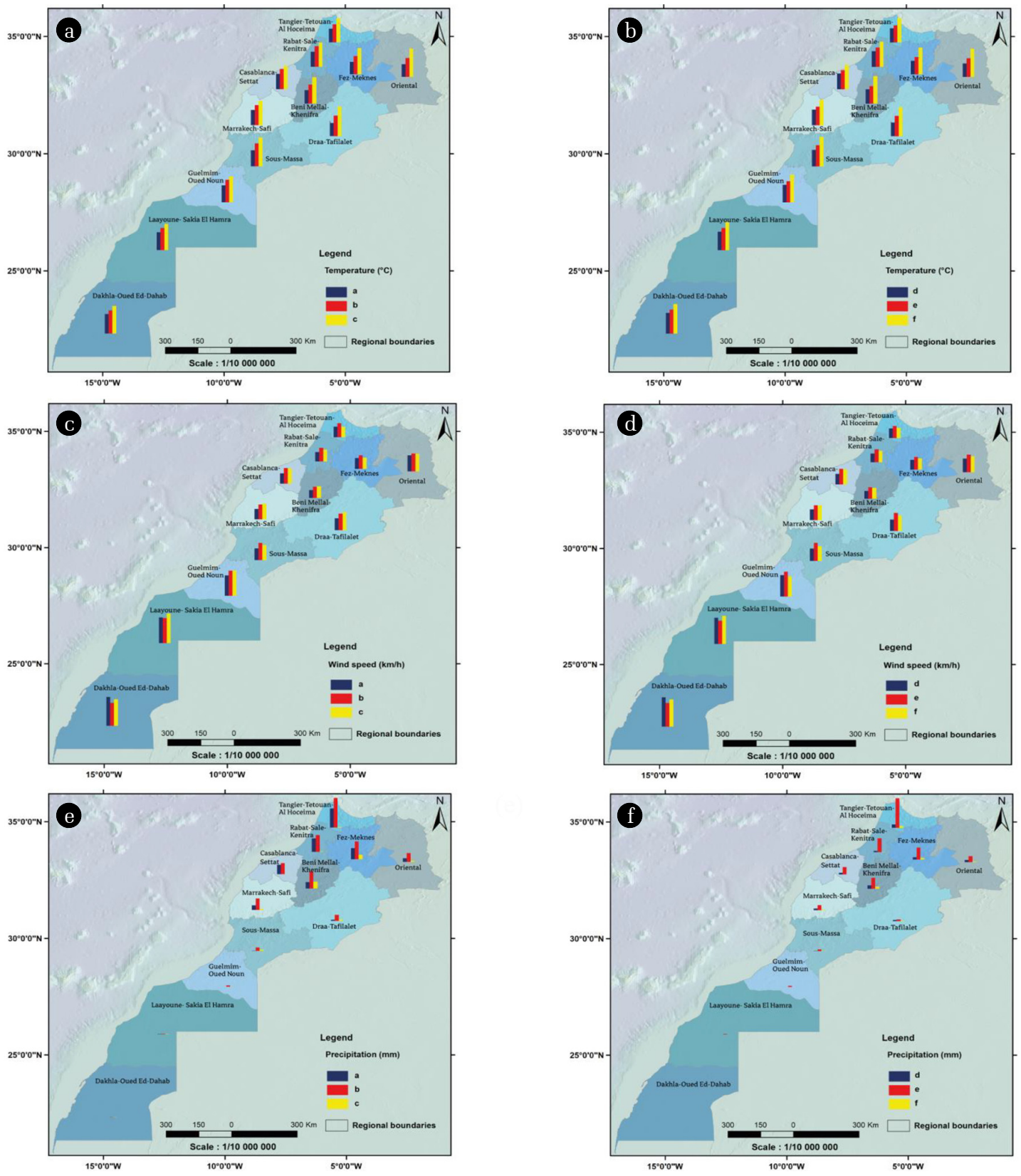

Fig. 1. (a), (c), (e) Meteorological data by region in 2019, and (b), (d), (f) 2020.

inant influence of transboundary pollution on the air quality of the northern cities of Morocco. Likewise, maritime traffic emissions, local, oceanic and Mediterranean are the origin of aerosols affecting northern Morocco [59]. Also, because of the high pressure in the north of Morocco which is illustrated in Fig. S1(b) showing a situation of stagnation of dust in this period.

The difference-in-difference analysis (Fig. 2(E) and Table S1) showed a sharp decrease in dust $\mathrm{PM}_{2.5}$ concentrations in 2020 compared to the same period in the past years (2016-2019) in the southern regions. This was recorded for the regions of Laayoune-Sakia El Hamra, Dakhla-Oued Ed-Dahab, and
Guelmim-Oued Noun (on average, 38.18, 27.39, and $10.23 \mu \mathrm{g} / \mathrm{m}^{3}$, respectively). The same results were raised in the head cities of the regions namely a reduction of $53.10,45.52$, and $4.59 \mu \mathrm{g} / \mathrm{m}^{3}$, respectively in Laayoune, Dakhla, and Guelmim. We also noticed a slight decrease in the regions of Rabat-Sale-Kenitra, TangierTetouan- Al Houceima, Casablanca-Settat, Fez-Meknes, Marrakech-Safi, and Beni Mellal-Khenifra with average concentrations of 2.52, 1.86, 1.76, $0.88,0.86$, and $0.1 \mu \mathrm{g} / \mathrm{m}^{3}$. On the other hand, we noticed a slight increase of $3.95,3.14$, and $0.27 \mu \mathrm{g} / \mathrm{m}^{3}$ in the Draa- Tafilalet, Oriental, and Souss- Massa regions. This justifies the results of the study which showed that particulate 

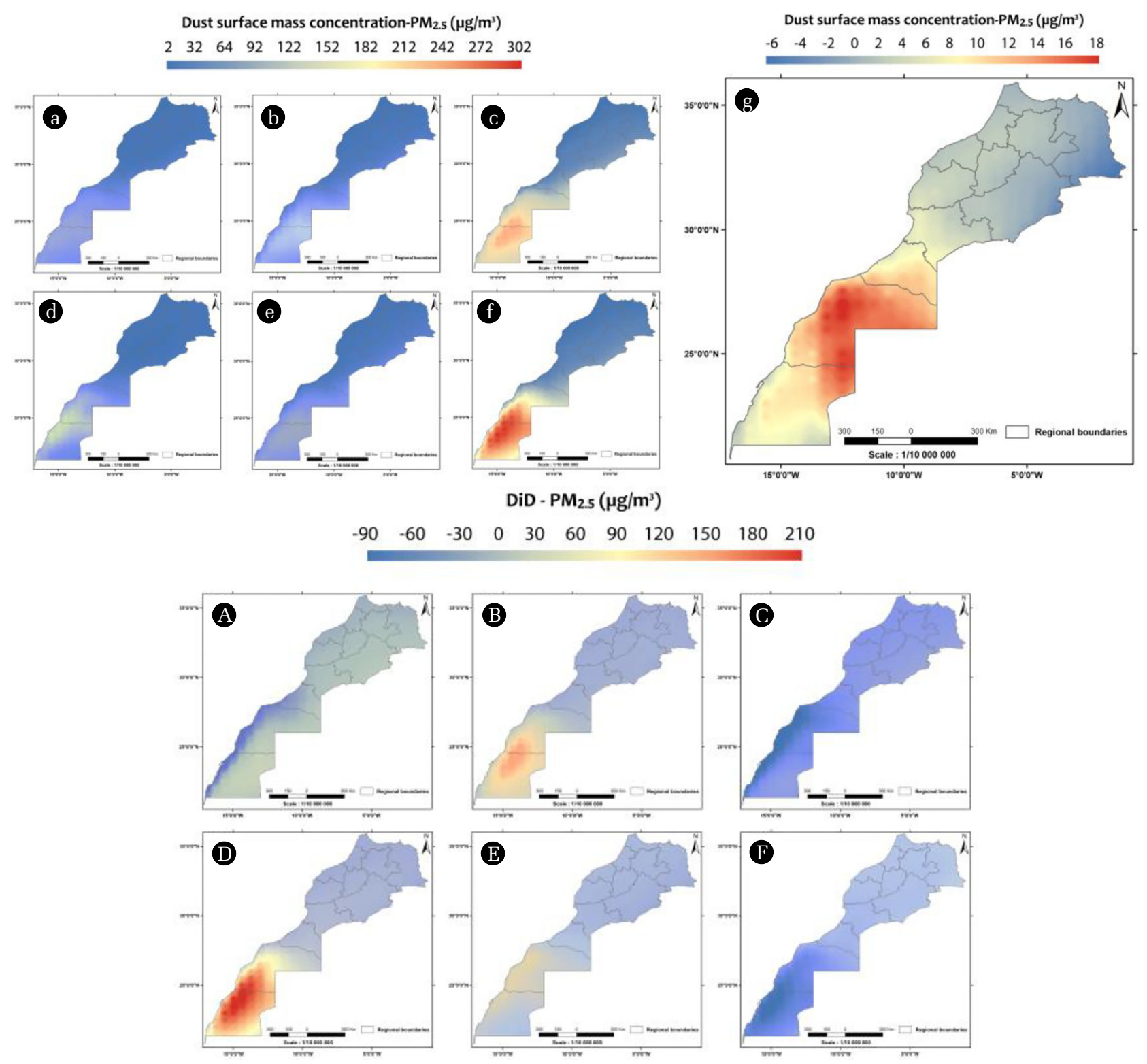

Fig. 2. Spatio-temporal evolution of dust surface mass concentration of $\mathrm{PM}_{2.5}$ in (2016-2019) and 2020, and the DiD approach.

pollution in Morocco is partly induced by a continental flow northeast to the southwest that is triggered by the Saharan trough and influenced by the high-pressure zone in the north (see Fig. S1) [37].

However, comparing the period after lockdown and during the lockdown in the Fig. 2(F), we find that the situation is reversed with an increase in the dust $\mathrm{PM}_{2.5}$ concentration in the southern regions which varies between 4.26 to $53.16 \mu \mathrm{g} / \mathrm{m}^{3}$. Dakhla city recorded the greatest increase in dust $\mathrm{PM}_{2.5}$ concentration, 45.94 $\mu \mathrm{g} / \mathrm{m}^{3}$ (Table S1). Furthermore, the other regions keep a slight decrease ranging from 0.13 to $3.56 \mu \mathrm{g} / \mathrm{m}^{3}$. This variation is mainly due to the natural sources of dust in the Saharan region in the south and the differences in measures taken after the lockdown for each region and province in Morocco. Also, because emissions of $\mathrm{PM}_{2.5}$ precursors increase at higher ambient temperatures
(Fig. 1) [60]. This variation during and after lockdown is recorded in several countries such as in India in Punjab and Chandigarh cities [26].

After comparing the trends of $\mathrm{PM}_{2.5}$ concentrations observed at the air quality measurement stations in Casablanca and Marrakech cities in a previous study [30] and that from MERRA. We concluded that both sources have the same trend, but MERRA data overestimates the observed trends from the measurement stations with an average of 15.76 and $13.73 \mu \mathrm{g} / \mathrm{m}^{3}$ in Casablanca and Marrakech cities, respectively.

Internationally, a study conducted in the 50 most polluted capital cities in the world showed that, during the lockdown, $\mathrm{PM}_{2.5}$ emissions decreased by $12 \%$ on average [61]. Also, another study conducted in India showed a reduction in $\mathrm{PM}_{2.5}$ levels of up to $-52 \%$ 

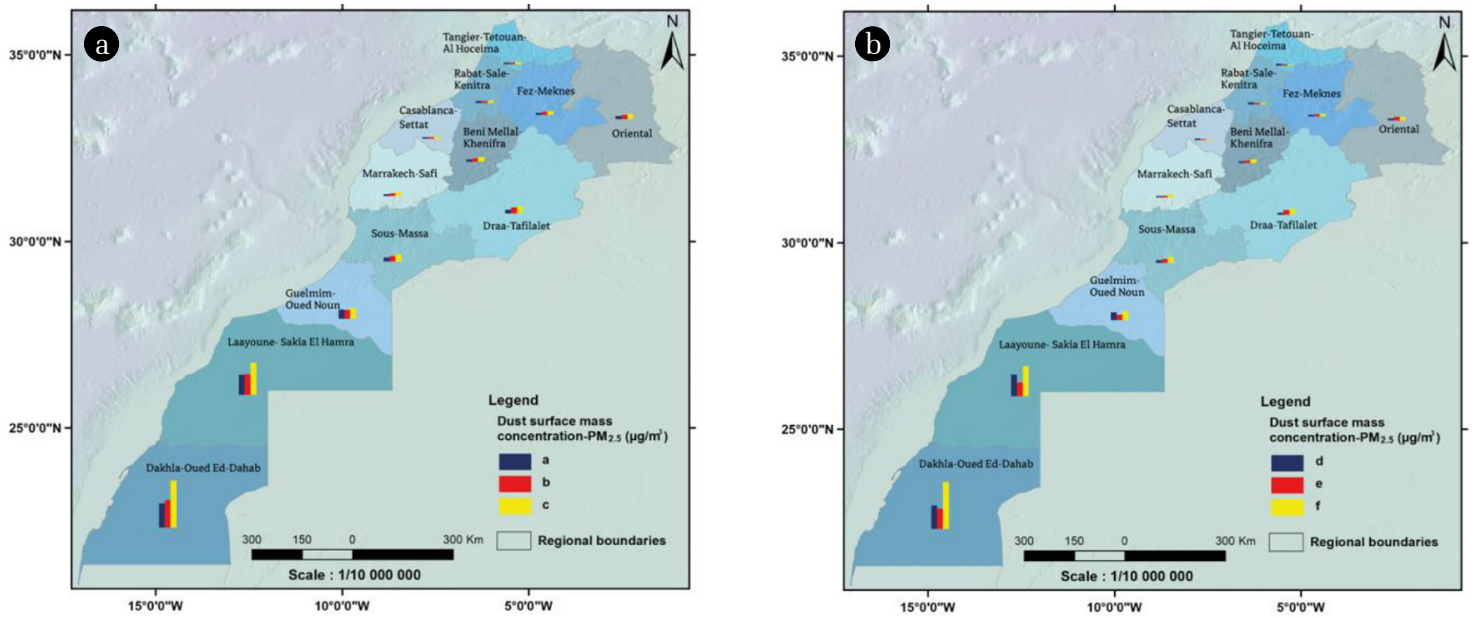

Fig. 3. Column histograms of the evolution of dust mass concentration- $\mathrm{PM}_{2.5}$ in the Moroccan regions in (a) 2016-2019 and (b) 2020.

during the lockdown. It also decreased drastically in the entire territory of Spain [62]. Furthermore, in China, $\mathrm{PM}_{2.5}$ concentration has decreased by 35, 29, and 19\% in Wuhan, Hubei (Wuhan excluded), and China (Hubei excluded), respectively [63]. Moreover, in Shanghai, China, a study shows that the reduction in anthropogenic emissions during the quarantine period manifested in an obvious reduction in the $\mathrm{PM}_{2.5}$ concentrations. This reduction can be mainly attributed to decreasing concentrations of nitrate and primary aerosols. On the other hand, the increasing contribution of secondary aerosols, and lower levels of NOx and nitrates did not completely avoid the haze in Shanghai during the epidemic [64].

Another study conducted in Pakistan, with a focus on four major cities (Islamabad, Lahore, Peshawar, and Karachi), have shown a substantial reduction in $\mathrm{PM}_{2.5}$ pollution levels (ranging from 13 to $33 \%$ in case of satellite observations, while 22 to $58 \%$ in ground-based observations) [65]. In Baghdad, during the $1^{\text {st }}$ partial and total lockdown, there was an 8 and 15\% reduction in $\mathrm{PM}_{2.5}$ and $\mathrm{PM}_{10}$ concentrations, respectively. Even under the low-traffic pollution, concentrations of these particles before and during the lockdown period exceeded the WHO daily limit values, providing evidence of the high contribution from non-traffic-related sources, such as natural sources and local dust [66].

In Chittagong city, Bangladesh, during the COVID-19 shutdown notable reduction of $40 \%$ compared to the daily mean concentration of the previous dry season was noticed for $\mathrm{PM}_{2.5}$ [21]. In Italy, depending on the region, $\mathrm{PM}_{2.5}$ showed reductions of $\sim 13-17 \%$ counterbalanced by increases up to $\sim 9 \%$ [42].

Besides, a study shows that even if anthropogenic activities were largely suppressed, fast chemical transformation of gaseous pollutants to secondary aerosols leads to air pollution. In addition to emission reduction measures, understanding the atmospheric oxidation process concerning secondary aerosol formation should be given more attention [64].

\subsection{Tropospheric Vertical Column of NO2}

In 2019, Fig. 4(a)-(c) and Fig. 5 show on average a downward trend in all regions. Fig. 4(A) shows a reduction in the tropospheric vertical column of $\mathrm{NO}_{2}$ in all regions except Laayoune- Sakia El
Hamra which recorded a slight increase in the order of $3 \%$. The large reductions are recorded in the regions of Tangier- TetouanAl Houceima (-32\%), Casablanca- Settat (-32\%), Rabat- Sale- Kenitra $(-30 \%)$ and Fez-Meknes (-23\%).

Fig. 4(B) shows that $\mathrm{NO}_{2}$ levels continued to decrease with low rates in seven (7) regions, namely Casablanca- Settat (-12\%), Rabat-Sale- Kenitra, and Dakhla- Oued Ed-Dahab (-10\%), and DraaTafilalet regions (-7\%). On the other hand, the rest of the regions saw a slight increase of up to $8 \%$ in the region of Fez-Meknes.

In Fig. 4(C), we note a decrease in the tropospheric vertical column of $\mathrm{NO}_{2}$ in the most populated regions [67]. These regions experience strong transport and industrial activities, namely the regions of Tangier- Tetouan-AL Houceima (-39\%), Casablanca-Settat (-37\%), Rabat-Sale- Kenitra (-16\%) and Marrakech- Safi (-14\%). This decrease, which varies between 2.19 and $8.68 \mu \mathrm{mol} / \mathrm{m}^{2}$, shows the importance of anthropogenic pollution caused by the industrial and transport sector that is the main source of this pollutant. However, Fig. 4(E) shows a slight decrease in the regions of Marrakech- Safi, Tangier- Tetouan- Al Houceima, and CasablancaSettat that vary between -78 and $-3 \%$. The great decrease is registered in Casablanca city $\left(16.01 \mu \mathrm{mol} / \mathrm{m}^{2}\right.$ - see Table S1).

After the lockdown period, the regions of Marrakech-Safi, Rabat-Sale- Kenitra, Casablanca- Settat, Tangier-Tetouan-Al Houceima, and Fez-Meknes experienced a small increase of tropospheric vertical column of $\mathrm{NO}_{2}$ at the order of 3.63, 3.16, 3.02, 2.8 and $1.08 \mu \mathrm{mol} / \mathrm{m}^{2}$ respectively (Fig. $4(\mathrm{~F})$ ). The great increase is registered in Casablanca city $\left(10.64 \mu \mathrm{mol} / \mathrm{m}^{2}\right.$ - see Table S1).This increase is mainly because of the return of some industrial activities and the removal of certain restrictions by the state. However, the southern regions (Dakhla- Oued Ed-Dahab and Laayoune-Sakia El Hamra) record a slight decrease on average in the order of -0.26 $\mu \mathrm{mol} / \mathrm{m}^{3}$.

During the second period (P2), all regions experienced a significant decrease varying between -3 and $-16 \%$ in 2020 compared to 2019 (see Fig. 4(G)), except for the regions of Fez-Meknes, DraaTafilalet, Dakhla-Oued Ed-Dahab, and the Oriental which experienced a slight increase on average to the order of $3 \%$. This increase may be due to soil emissions and the input of this pollutant through 


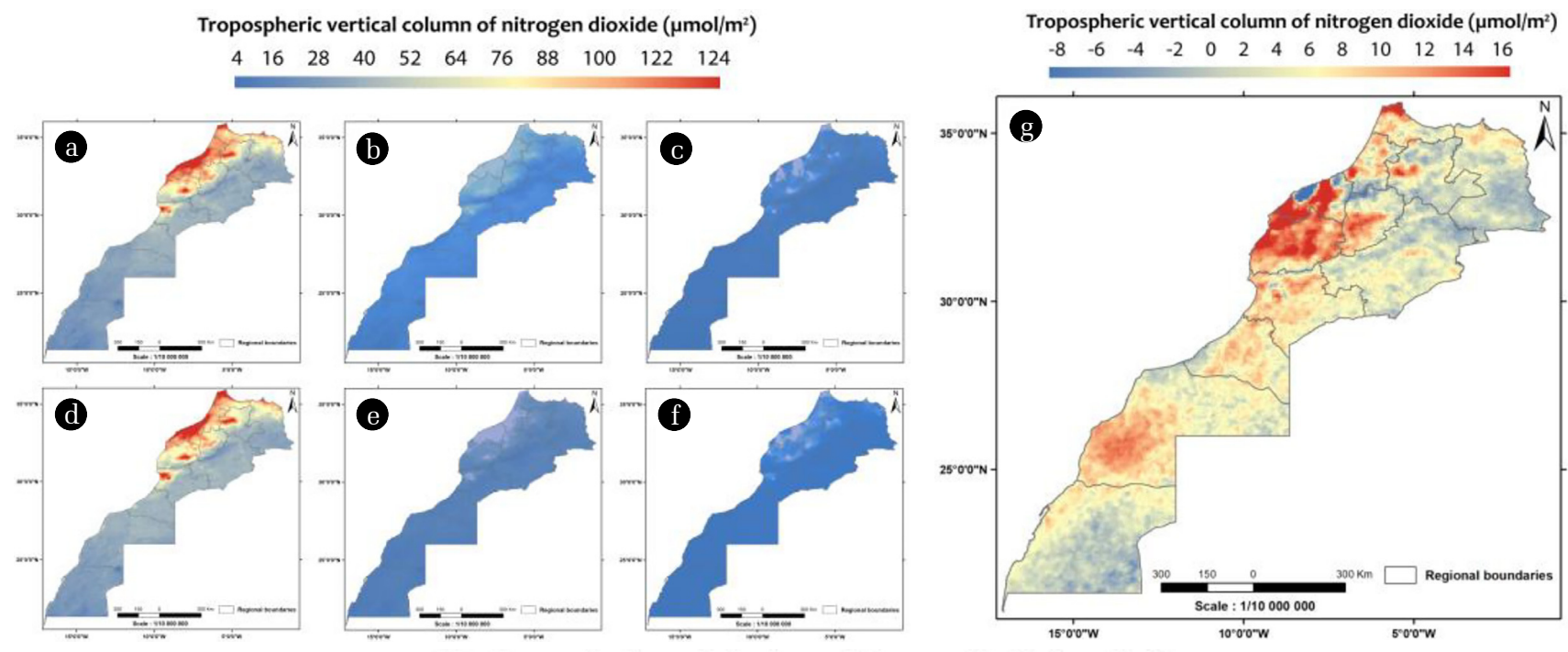

DiD - Tropospheric vertical column of nitrogen dioxide $\left(\mu \mathrm{mol} / \mathrm{m}^{2}\right)$ $\begin{array}{lllllllllll}-80 & -70 & -60 & -50 & -40 & -30 & -20 & -10 & 0 & 10 & 20\end{array}$
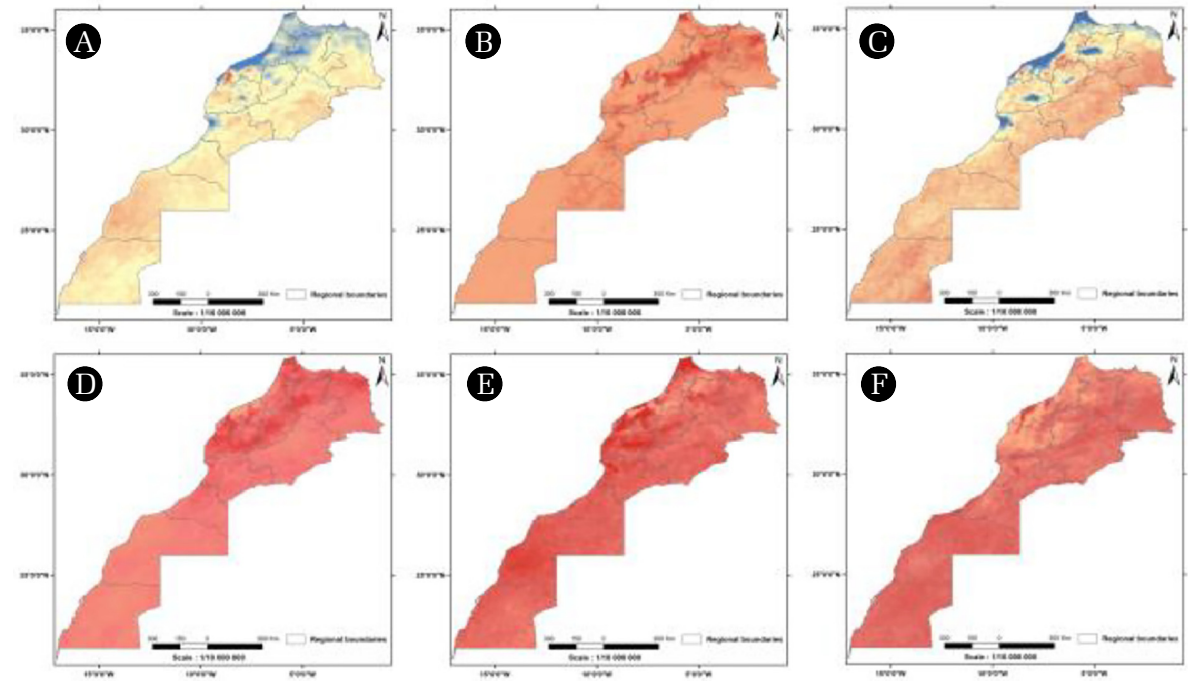

Fig. 4. Spatio-temporal evolution of tropospheric vertical column of nitrogen dioxide in 2019 and 2020, and the DiD approach.

surrounding areas due to the high pressure (See Fig. S1).

Similar results are also reported on an international scale during the lockdown, such as in Baghdad and Iraq (reduction up to 35 to $40 \%$ of $\mathrm{NO}_{2}$ tropospheric column). This is mainly due to transportation restrictions and industry emission slowdown [66].

In India, in urban centers, an average of $46 \%$ reduction of $\mathrm{NO}_{2}$ was observed in eight cities during the first lockdown phase [68]. However, in Punjab and Chandigarh, $\mathrm{NO}_{2}$ was reduced during the first lockdown, but remained variable between cities and different phases of lockdown and unlock periods [26]. In Spain, a study indicates a significant correlation between the population's activity level and the reduction of $\mathrm{NO}_{2}$ values [69]. This decrease was drastic in the entire territory of Spain [62].

A reduction in $\mathrm{NO}_{2}$ concentrations (-13\%) was observed as a consequence of the COVID-19 lockdown in Ecuador. However, this reduction was most apparent in the cases of Guayaquil (-23.4\%) and Quito (-22.4\%), the two most highly populated cities [70]. In the United Arab Emirates, a study showed that during lockdown periods, $\mathrm{NO}_{2}$ concentration decreased by $23.7 \%$ compared to the same period in 2019 [71].

Several studies presented a large decrease of $\mathrm{NO}_{2}$ concentration during the lockdown period in China from both in situ and satellite observations [72, 73]. In eastern China, where the 36 biggest Chinese cities are located, a study used a method to calculate the pollution back to the sources of the emissions to the $\mathrm{NO}_{2}$ pollutant. Almost all of these cities experienced significant emission reductions of 20-50\% during the lockdown in February 2020. In addition to urban China, there was an average $40 \%$ reduction in emissions compared to coal-fired power plants and a reduction in shipping from 15 to $40 \%$ depending on the region [74]. The average concen- 

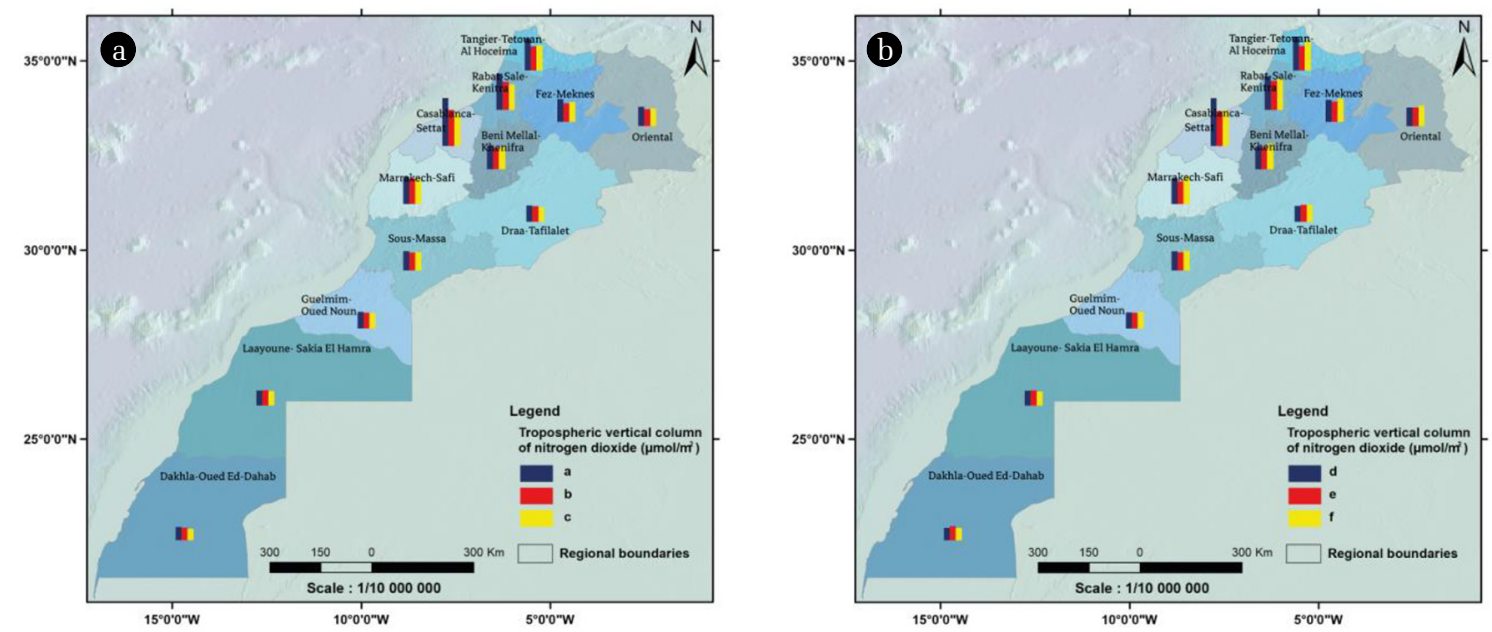

Fig. 5. Column histograms of the evolution of tropospheric vertical column of nitrogen dioxide in the Moroccan regions in (a) 2019 and (b) 2020.

tration of $\mathrm{NO}_{2}$ in early 2020 during the COVID-19 epidemic has decreased by 53, 50, and 30\% in Wuhan city, Hubei Province (Wuhan excluded), and China (Hubei excluded), respectively [63].

In Italy, $\mathrm{NO}_{2}$ levels remarkably dropped overall urban areas (from $-24.9 \%$ in Milan to $-59.1 \%$ in Naples), to an extent roughly proportional but lower than traffic reduction [42]. In Chittagong city, Bangladesh, During the COVID-19 shutdown, a notable reduction of $13 \%$ compared to the daily mean concentration of the previous dry season was recorded in $\mathrm{NO}_{2}$ [21].

In addition, the decrease in $\mathrm{NO}_{\mathrm{x}}$ emissions during COVID-19 containment is complicated by several factors such as meteorology and seasonal variations from winter to spring in the Northern Hemisphere [75] as well as emissions from other sectors not affected by COVID-19 such as electricity generation, agriculture and other natural sources (e.g. plants, forest fires, dust, volcanoes) [76].

Morocco is probably affected by natural reductions in $\mathrm{NO}_{\mathrm{x}}$ due to seasonal variations and the accumulation of effect, especially due to the improvement of the vehicle fleet in recent years.

Similarly, other studies have shown that $\mathrm{NO}_{\mathrm{x}}$ emission reductions in North America, Europe, and China are responsible for the long-term decline in $\mathrm{NO}_{\mathrm{x}}[77,78]$.

\subsection{Total Ozone Column}

Total column ozone (TCO) at any location on the globe is found by measuring all the $\mathrm{O}_{3}$ in the atmosphere directly above that location. The spatial dependence of TCO varies strongly with latitude with the highest values occur at the middle and high latitudes [79]. In Morocco, we noticed this spatial variation with high values in the north and center of Morocco and average values in the southern regions (Figs. 6 and 7).

On one hand, Fig. 6(A) and (C) show an increasing trend in all regions of Morocco for 2019 and 2020. In 2020, we notice that the increase was minimal in comparison with 2019, with an average difference of around -26.17 DU (-71\%) and a maximum reduction recorded in the region of Tangier-Tetouan-Al Houceima of 34.84 DU (-73\%) (Fig. 6(E)). These results concur with the study showing that fluctuations in the trend of total $\mathrm{O}_{3}$ at the mid-latitude belt are large in winter, and this is probably due to the dynamic processes that occur during this season such as planetary wave activity [80].

On the other hand, Fig. 6(B) and (D) show a downward trend in all regions of Morocco except for the region of Dakhla-Oued Ed-Dahab, which recorded a slight increase during 20191.33 DU; $+0.47 \%$. Conversely to the P1, in 2020 , we notice a strong decrease in comparison with 2019 with an average difference in the order of $-10.58 \mathrm{DU}$ and a maximum reduction recorded in the region of Souss-Massa 15.29DU, with a value of about 18.16 DU in Agadir city (Fig. 6(F) and Table S1).

Precisely during the second period, Fig. 6(G) shows a slight decrease of TCO in all regions of Morocco (around -1\%), except for the regions of Dakhla- Oued Ed-Dahab, Souss- Massa and GuelmimOued Noun which experienced a slight increase during the lockdown period (1.1, 0.5, 0.2\%, respectively). Also, the other southern regions namely Draa- Tafilalet and Laayoune- Sakia El Hamra recorded slight decreases during this period $(-0.08,-0.16 \%$, respectively).

This reduction during the lockdown can be explained on the one hand, by the small increase in wind speed during 2020 (Fig. 1), which allows the natural movements of the air to mix and combine the air between the regions to high $\mathrm{O}_{3}$ values and those with low $\mathrm{O}_{3}$ values in the stratosphere. The tropospheric weather systems reduce temporarily the thickness of the stratospheric $\mathrm{O}_{3}$ layer and therefore lower the TCO. Also, due to the changes in the balance of atmospheric chemicals as the air moves to different places [81]. On the other hand, the slight increase recorded in the southern regions at mid-latitudes compared to the center and north of Morocco is explained by the slow atmospheric circulation known as the Brewer-Dobson circulation which allows $\mathrm{O}_{3}$ to be displaced from the tropics where it is found occurs towards mid and polar latitudes [82]. Also by intercontinental land transport which can transport $\mathrm{O}_{3}$ from Europe since it has a lifespan of several days. Most of the $\mathrm{O}_{3}$ production occurs in the tropical stratosphere through the reactions below:

$$
\begin{gathered}
\mathrm{O}_{2}+\mathrm{h} v \rightarrow \mathrm{O}+\mathrm{O} \\
\mathrm{O}+\mathrm{O}_{2} \rightarrow \mathrm{O}_{3}
\end{gathered}
$$



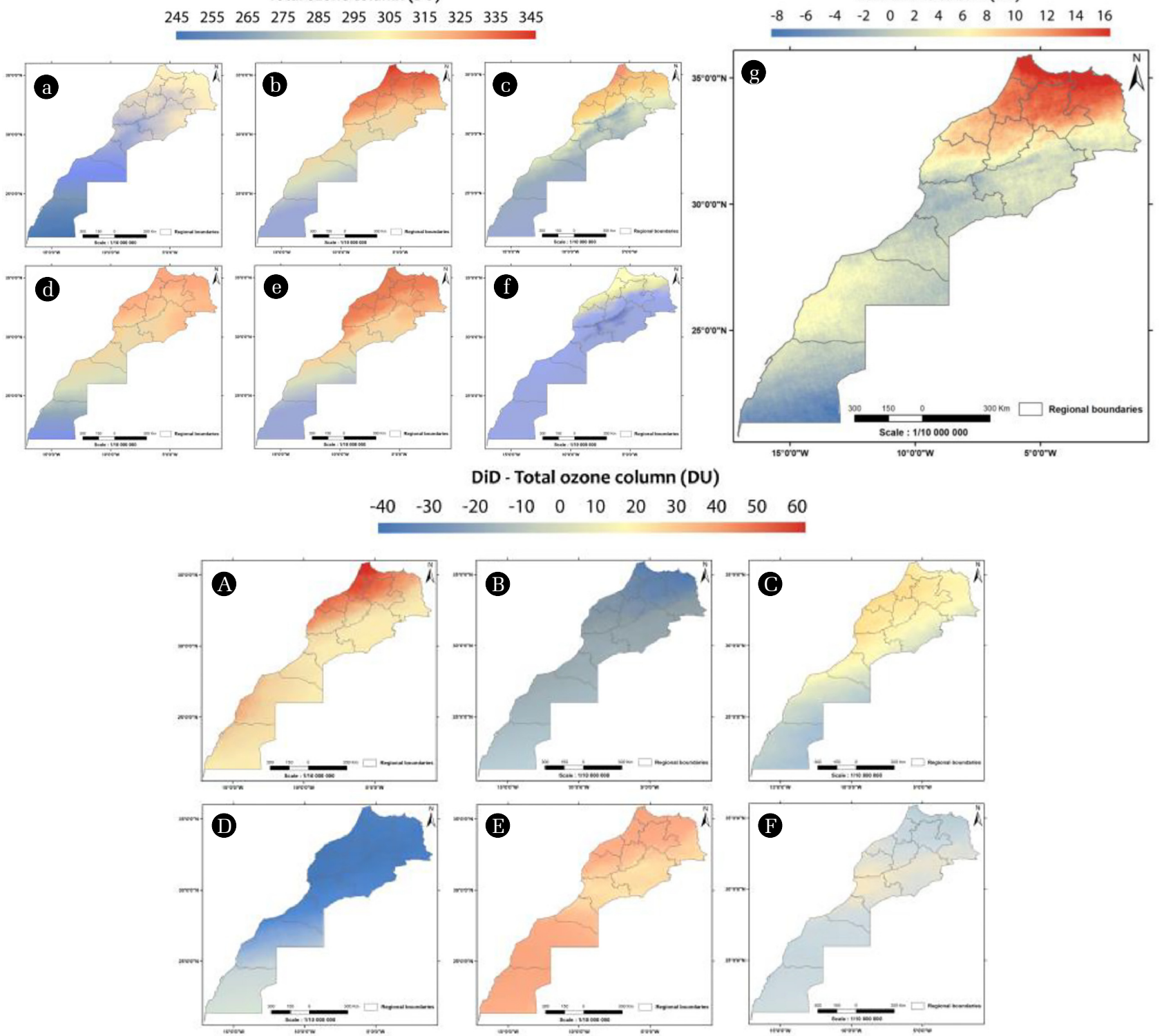

Fig. 6. Spatio-temporal evolution of total ozone column in 2019 and 2020, and the DiD approach.

Other factors are also responsible for the increase of $\mathrm{O}_{3}$, namely the increase of sunshine and temperatures (from February to April), the decrease of $\mathrm{NO}$ which reduces the consumption of $\mathrm{O}_{3}$ (the titration, $\mathrm{NO}+\mathrm{O}_{3} \rightarrow \mathrm{NO}_{2}+\mathrm{O}_{2}$ ). Finally, the factor relating to the heterogeneous reactions on the fine particles. These particles as scavengers of the peroxyl radicals $\left(\mathrm{HO}_{2}, \mathrm{RO}_{2}\right)$ ensure the conversion of $\mathrm{NO}$ into $\mathrm{NO}_{2}$ (responsible for the production of $\mathrm{O}_{3}$ ).

The increase in surface $\mathrm{O}_{3}$ during the lockdown found by several studies is explained by the decrease in $\mathrm{NO}_{\mathrm{x}}$ and other gases linked to human activity, which consumes $\mathrm{O}_{3}$ [83]. Thus, the increase in solar radiation, temperature, and humidity favoured the formation of $\mathrm{O}_{3}$. Besides, the increase in temperature increases the emissions of BVOCs such as isoprene. Also, volatile organic compounds (VOCs) and $\mathrm{SO}_{2}$ remain almost stable and the oxidation of these species leads to the formation of $\mathrm{O}_{3}$ and organic aerosol, which also explains the increase in PM during lockdown [84].

At the international level, several countries have found similar results, namely in Spain [62], China [63, 64], and in Irak [66] which indicate that $\mathrm{O}_{3}$ concentration increase during the quarantine period when $\mathrm{NO}_{\mathrm{x}}$ and $\mathrm{PM}$ dropped, indicating that coordinated control of other pollutants is needed. Likewise, In Punjab and Chandigarh, India, surface-level $\mathrm{O}_{3}$ resulted in an overall increase trend during the lockdown and unlock phases [26].

Conversely in Italy, $\mathrm{O}_{3}$ concentrations remained unchanged or even increased (up to $13.7 \%$ in Palermo and $14.7 \%$ in Rome), likely because of the reduced $\mathrm{O}_{3}$ titration triggered by lower $\mathrm{NO}$ emissions from vehicles, and lower NOx emissions over typical VOCs- limited environments such as urban areas, not compensated 

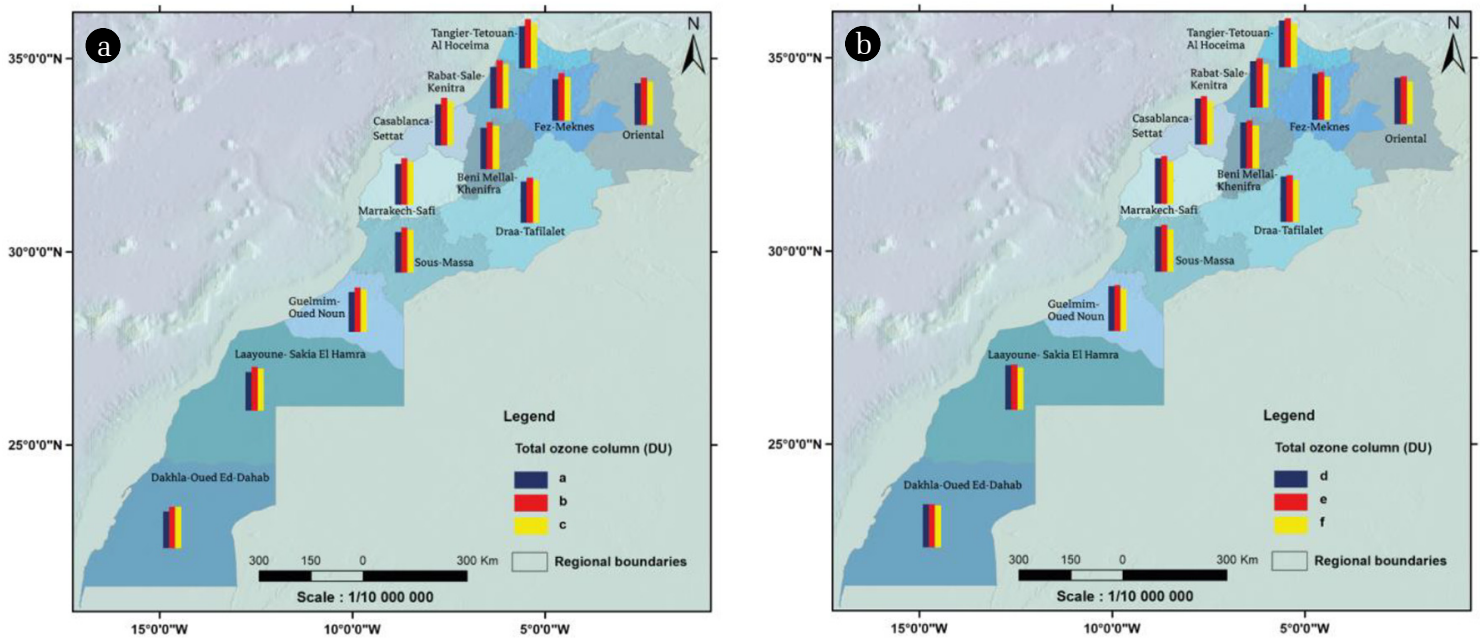

Fig. 7. Column histograms of the evolution of total ozone column in the Moroccan regions in (a) 2019 and (b) 2020.

by comparable VOCs emissions reductions [42].

The results of this study showed a significant reduction in air pollution, which remains relative to the state of each region. This result goes in the same direction with the study showing that the reduction of air pollution in Morocco is relative for each city according to the sources of emission, and therefore it is necessary to study each city in isolation to improve air quality [85]. Noted that the comparison of our results with the results of other countries is included for information and benchmark and that each country has different weather conditions and emission sources.

However, DiD approach used is a method that is based on several simplifications and assumptions liable to bias the estimates by canceling the effects of weather conditions on air pollution as shown by the comparison study on 48 Spanish provinces [86]. We added the study of meteorological data at the national level to mitigate this bias, but these results must be deepened and studied for each zone including the corresponding meteorological data.

\section{Conclusions}

The main objective of this paper is to study the effects of the COVID-19 lockdown measures on air quality, by analyzing dust $\mathrm{PM}_{2.5}, \mathrm{NO}_{2}$, and $\mathrm{O}_{3}$ during 3 periods. According to this study, the COVID-19 lockdown has a positive effect on air quality in Morocco.

During the lockdown period, the dust surface $\mathrm{PM}_{2.5}$ mass concentration and the tropospheric $\mathrm{NO}_{2}$ vertical column were reduced by an average of -10 and $-4 \%$, respectively. However, the total $\mathrm{O}_{3}$ column showed a slight increase (on average 1\%). This can be mainly attributed to the measures taken by the Moroccan government by limiting human activities, namely transport and industrial activities, and also by meteorological factors and natural effects. Similarly, through the accumulation of effects, especially due to the improvement of the vehicle fleet in recent years and the reduction of the infiltration of pollutants from other neighbouring countries that they have also been in lockdown.

This COVID19 scenario provided an unprecedented opportunity to assess the impact of a remarkable and prolonged ( $\sim 3$ months) reduction in anthropogenic emissions on air quality. This is a great opportunity to understand some situations related to quality despite the lack of studies in the region. The results of this study should be taken into account by governments and policymakers to strengthen national and international environmental strategies, define regulatory laws that adapt to the current situation. Also, to find a compromise between the tangible benefits of air quality and ongoing development strategies, as well as to develop effective policies for reducing emissions and preventing air pollution. These policies must be based on the adoption of local measures to achieve global objectives and adopt new attitudes. There is also an urgent need to establish a comprehensive national emissions inventory and conduct in-depth studies.

This study also confirmed the complex nature of air pollution. Even with the isolation and control of the main sources of emissions, there is still a need to provide consistent decarbonization efforts across all emission sectors to truly improve air quality and public health.

The authors show that the particulate pollution in Morocco is partly due to synoptic weather factors. A significant part of dust particulate pollution and the total vertical column of $\mathrm{NO}_{2}$ are mainly incoming from the northern and northern- eastern borders of Morocco.

To remedy this situation and improve air quality, the authors recommend the establishment of a remote work integration plan in the private sector. Moreover, the state to minimize transportation, the encouragement of the use of electronic vehicles, and the enhancement and encouragement of the use of adequate public transport are also desired. The authors also recommend encouraging companies to conduct their activities remotely when possible. Also, increasing the number of event days (day without a car, bike day, etc.) must be taken into account, as well as, providing more funds to scientific research, specifically that related to air quality. 


\section{Acknowledgments}

We acknowledge the Analysis Infrastructure (Giovanni) and ESA for providing us the MERRA-2, the Sentinel-5 P/TROPOMI and ERA5 products. The authors gratefully acknowledge the Copernicus programme. This research did not receive any specific grant from funding agencies in the public, commercial, or not-for-profit sectors.

\section{Author Contributions}

I.S (Ph.D. student) conducted all the experiments, analyzed the data, and wrote the manuscript. L.I. (Professor) revised the manuscript. K.K. (Ph.D.) contributed to the design of the experiment and implementation of the research. S.F. (Ph.D. student) assisted in uploading data and revised the manuscript. M.E. (Ph.D. student) creates the maps. M.T. (Professor) revised the manuscript.

\section{References}

1. World Health Organization. Coronavirus Disease (COVID-19) Dashboard [internet]. c2020[cited 06 January 2021]. Available from: https://covid19.who.int/.

2. Anderson RM, Heesterbeek H, Klinkenberg D, Hollingsworth TD. How will country-based mitigation measures influence the course of the COVID-19 epidemic? Lancet. 2020;395:931-934.

3. DCAF C. Management of the state of health emergency in Morocco (in French) [internet]. [Cited 20 January 2021]. Available from: https:/www. dcaf.ch/sites/default/files/imce/ Rapport COvid 19 version FR.pdf.

4. MAP. What is the difference between containment and a state of health emergency in Morocco? (in French). [internet]. c2020 [cited 12 July 2021]. Available from: https://www.maroc.ma/fr/ actualites/quelle-est-la-differenceentre-confinement-et-etatdurgence-sanitaire-au-maroc.

5. Minister. Law no. 13-03 relating to the fight against air pollution; 2003. p. 1-4.

6. Ministry of the Interior and Ministry of the Environment. Joint Order setting out the information thresholds, alert thresholds and the procedures for applying emergency measures relating to air quality monitoring; 2015. p. 2968-2969.

7. The first Minister. Decree n 2-09-631 of 23 Rejeb 1431 (July $6,2010)$ setting the limit values for the release, emission or discharge of pollutants in air from stationary sources of pollution and how they are controlled; 2010. p. 1-14.

8. The Environment Department. National Air Quality Monitoring Network (in French) [Internet]. 2018 [cited 30 December 2020]. Available from: https://www.environnement. gov.ma/images/AIR/Programme_National_de_lAir_PNAir-min.pdf.

9. The Environment Department. Air [Internet]. 2020 [cited 20 July 2021]. Available from: http://environnement.gov.ma/fr/air.

10. Minister of the Environment. 3rd report on the state of the environment of Morocco; 2015. p. 134-136.

11. The Minister of Energy, Mines, Water and the Environment and the Minister of Health. Joint order setting the conditions and methods of calculating the air quality index; 2009. p. 1-6.

12. Isaifan RJ. The dramatic impact of coronavirus outbreak on air quality: Has it saved as much as it has killed so far? Glob. J. Environ. Sci. Manag. 2020;6:275-288.

13. Larnaud N. Satellite animation shows air pollution in China and Italy clearing amid coronavirus lockdowns [Internet]. 2020 [cited 20 March 2020]. Available from: https://www.cbsnews. com/news/coronavirus-satellite-animation-shows-pollutionclearing-over-china-and-italy/

14. Coker ES, Cavalli L, Fabrizi E, et al. The Effects of Air Pollution on COVID-19 Related Mortality in Northern Italy. Environ. Resour. Econ. 2020;76:611-634.

15. Zoltán Massay-Kosubek. Air pollution is decreasing around the world - maps (in French). European public health alliance; 2020. p. 1-2.

16. Baldasano JM. COVID-19 lockdown effects on air quality by NO 2 in the cities of Barcelona and Madrid (Spain). Sci. Total Environ. 2020;741:140353.

17. Ogen Y. Assessing nitrogen dioxide (NO2) levels as a contributing factor to coronavirus (COVID-19) fatality. Sci. Total Environ. 2020;726:138605.

18. Berman JD, Ebisu K. Changes in U.S. air pollution during the COVID-19 pandemic. Sci. Total Environ. 2020;739:139864.

19. Bernstein JA, Alexis N, Barnes C, et al. Health effects of air pollution. J. Allergy Clin. Immunol. 2004;114:1116-1123.

20. Liu Q, Harris JT, Chiu LS, et al. Spatiotemporal impacts of COVID-19 on air pollution in California, USA. Sci. Total Environ. 2021;750:141592.

21. Masum MH, Pal SK. Statistical evaluation of selected air quality parameters influenced by COVID-19 lockdown. Glob. J. Environ. Sci. Manag. 2021;6:85-94.

22. Sharma R, Shrestha UB, Sharma R, Bhattarai S, Tran HNT, Rupakheti M. Lockdown Caused by COVID-19 Pandemic Reduces Air Pollution in Cities Worldwide. Preprint. 2020;1-25. (doi:10.31223/osf.io/edt4j)

23. Filippini T, Rothman KJ, Goffi A, et al. Satellite-detected tropospheric nitrogen dioxide and spread of SARS-CoV-2 infection in Northern Italy. Sci. Total Environ. 2020;739:140278.

24. Ogen Y. Assessing nitrogen dioxide (NO2) levels as a contributing factor to coronavirus (COVID-19) fatality. Sci. Total Environ. 2020;726:138605.

25. Wu X, Nethery RC, Sabath MB, Braun D, Dominici F. Exposure to air pollution and COVID-19 mortality in the United States: A nationwide cross-sectional study. medRxiv : the preprint server for health sciences. 2020;45(6):1-6.

26. Sahoo PK, Chauhan AK, Mangla S, Pathak AK, Garg VK. COVID-19 pandemic: An outlook on its impact on air quality and its association with environmental variables in major cities of Punjab and Chandigarh, India. Environ. Forensics. 2021;22(1):143-154.

27. Zoran MA, Savastru RS, Savastru DM, Tautan MN. Assessing the relationship between surface levels of PM2.5 and PM10 particulate matter impact on COVID-19 in Milan, Italy. Sci. Total Environ. 2020;738:139825.

28. Sohrabi C, Alsafi Z, O'Neill N, et al. World Health Organization declares global emergency: A review of the 2019 novel coronavirus (COVID-19). Int. J. Surg. 2020;76:71-76. 
29. P M and EA. How Countries of South Mitigate COVID-19: Models of Morocco and Kerala, India. Electron. Res. J. Soc. Sci. Humanit. 2020;2:16-28.

30. Khomsi K, Najmi H, Amghar H, Chelhaoui Y, Souhaili Z. COVID-19 national lockdown in morocco: Impacts on air quality and public health. One Heal. 2021;11:100200.

31. Otmani A, Benchrif A, Tahri M, et al. Impact of Covid-19 lockdown on PM10, SO2 and NO2 concentrations in Salé City (Morocco). Sci. Total Environ. 2020;735:139541.

32. Elass K, Eddaif A, Radey O, Aitzaouit O, Yakoubi ME, Chelhaoui Y. Effect of restricted emissions during covid-19 lockdown on air quality in Rabat - Morocco. Glob. Nest J. 2020;22:348-353.

33. Wang P, Chen K, Zhu S, Wang P, Zhang H. Severe air pollution events not avoided by reduced anthropogenic activities during COVID-19 outbreak. Resour. Conserv. Recycl. 2020;158:104814.

34. Sicard P, De Marco A, Agathokleous E, et al. Amplified ozone pollution in cities during the COVID-19 lockdown. Sci. Total Environ. 735:139542.

35. Mahato S, Pal S, Ghosh KG. Effect of lockdown amid COVID-19 pandemic on air quality of the megacity Delhi, India. Sci. Total Environ. 2020;730:139086.

36. Schilling J, Freier KP, Hertig E, Scheffran J. Climate change, vulnerability and adaptation in North Africa with focus on Morocco. Agric. Ecosyst. Environ. 2012;156:12-26.

37. Khomsi K, Najmi H, Chelhaoui Y, Souhaili Z. The contribution of large-scale atmospheric patterns to pm10 pollution: The new saharan oscillation index. Aerosol Air Qual. Res. 2020;20:1038-1047.

38. Stour L, Agoumi A. Climatic drought in Morocco during the last decades. Hydroécol. Appl. 2008;16:215-232.

39. High Commission for Planning. Population clock [Internet]; c2020 [cited 30 November 2020]. Available from: https://www. hcp.ma/.

40. Xiao Wu et al. Exposure to air pollution and COVID-19 mortality in the United States: A nationwide cross-sectional study. J. Chem. Inf. Model. 2020;53:1689-1699.

41. Firmansyah H, Fadlillah AN, Pawitra AS. Particulate Matter as a Driven Factor Covid19 Transmission at Outdoor: Review. J. Kesehat. Lingkung. 2020;12:225.

42. Gualtieri G, Brilli L, Carotenuto F, Vagnoli C, Zaldei A, Gioli B. Quantifying road traffic impact on air quality in urban areas: A Covid19-induced lockdown analysis in Italy. Environ. Pollut. 2020;267:115682.

43. The European Space Agency. Sentinel-5P [internet]. 2020 [cited 25 February 2021]. Available from: https://sentinel.esa.int/web/ sentinel/missions/sentinel-5p.

44. Sekmoudi I, Khomsi K, Faieq S, Idrissi L. Assessment of global and regional PM10 CAMSRA data: comparison to observed data in Morocco. Environ. Sci. Pollut. Res. 2021;28:29984-29997.

45. Pawson S. Modern-Era Retrospective analysis for Research and Applications, [internet]. Version 2; 2019 [cited 25 February 2021]. Available from: https://gmao.gsfc. nasa.gov/reanalysis/ MERRA-2/.

46. Gelaro R, McCarty W, Suárez MJ, et al. The modern-era retrospective analysis for research and applications, version 2 (MERRA-2). J. Clim. 2017;30:5419-5454.

47. Buchard V, Randles CA, da Silva AM, et al. The MERRA-2 aerosol reanalysis, 1980 onward. Part II: Evaluation and case studies. J. Clim. 2017;30:6851-6872.

48. Carmona JM, Gupta P, Lozano-García DF, Vanoye AY, Yépez FD, Mendoza A. Spatial and Temporal Distribution of PM2.5 Pollution over Northeastern Mexico: Application of MERRA-2 Reanalysis Datasets. Remote Sens. 2020:12(14):2286.

49. ECMWF COPERNICUS. ERA5 [internet]. 2020 [cited 25 February 2021]. Available from: https://www. ecmwf.int/en/ forecasts/datasets/reanalysis-datasets/era5.

50. Childs C. Interpolating Surfaces in ArcGIS Spatial Analyst. ArcUser 2004; 32-35.

51. Zheng Z, Yang Z, Wu Z, Marinello F. Spatial variation of NO2 and its impact factors in China: An application of sentinel-5P products. Remote Sens. 2019;11:1-24.

52. Shukla K, Kumar P, Mann GS, Khare M. Mapping spatial distribution of particulate matter using Kriging and Inverse Distance Weighting at supersites of megacity Delhi. Sustain. Cities Soc. 2020;54:101997.

53. Ryu JS, Kim MS, Cha KJ, Lee TH, Choi DH. Kriging interpolation methods in geostatistics and DACE model. KSME Int. J. 2002;16:619-632.

54. Dimick JB, Ryan AM. Methods for evaluating changes in health care policy: The difference-in-differences approach. JAMA - J. Am. Med. Assoc. 2014;312:2401-2402.

55. Nawaz MA, Seshadri U, Kumar P, Aqdas R, Patwary AK, Riaz $\mathrm{M}$. Nexus between green finance and climate change mitigation in N-11 and BRICS countries: empirical estimation through difference in differences (DID) approach. Environ. Sci. Pollut. Res. 2021;28:6504-6519.

56. Theil H. A Rank-Invariant Method of Linear and Polynomial Regression Analysis. In: Raj B, Koerts J, eds. Henri Theil's Contributions to Economics and Econometrics. Advanced Studies in Theoretical and Applied Econometrics. Dordrecht: Springer; 1992. p. 345-381.

57. Sen PK. Estimates of the Regression Coefficient Based on Kendall's Tau. J. Am. Stat. Assoc. 1968;63:1379-1389.

58. Khomsi K, Najmi H, Amghar H, Chelhaoui Y, Souhaili Z. COVID-19 national lockdown in morocco: Impacts on air quality and public health. One Heal. 2021;11:100200.

59. Benchrif A, Guinot B, Bounakhla M, Cachier H, Damnati B, Baghdad B. Aerosols in Northern Morocco: Input pathways and their chemical fingerprint. Atmos. Environ. 2018;174: 140-147.

60. Climate change, air quality, and human health. Am. J. Prev. Med. 2008;35(5):459-467

61. Rodríguez-Urrego D, Rodríguez-Urrego L. Air quality during the COVID-19: PM2.5 analysis in the 50 most polluted capital cities in the world. Environ. Pollut. 2020;266:115042.

62. Martorell-Marugán J, Villatoro-García JA, García-Moreno A, et al. DatAC: A visual analytics platform to explore climate and air quality indicators associated with the COVID-19 pandemic in Spain. Sci. Total Environ. 2021;750:141424.

63. Chu B, Zhang S, Liu J, Ma Q, He H. Significant concurrent decrease in PM2.5 and NO2 concentrations in China during COVID-19 epidemic. J. Environ. Sci. (China). 2021;99:346-353.

64. Chen H, Huo J, Fu Q, Duan Y, Xiao H, Chen J. Impact of quarantine measures on chemical compositions of PM2.5 during the COVID-19 epidemic in Shanghai, China. Sci. Total Environ. 
2020;743:140758.

65. Ali SM, Malik F, Anjum MS, et al. Exploring the linkage between PM2.5 levels and COVID-19 spread and its implications for socio-economic circles. Environ. Res. 2020;193:110421.

66. Hashim BM, Al-Naseri SK, Al-Maliki A, Al-Ansari N. Impact of COVID-19 lockdown on NO2, O3, PM2.5 and PM10 concentrations and assessing air quality changes in Baghdad, Iraq. Sci. Total Environ. 2020;193:110421.

67. RGPH. Legal population of the regions, provinces, prefectures, municipalities, districts and communes of the kingdom according to the results of the RGPH 2014 (12 regions) (in French) [internet]. 2014 [cited 25 February 2021]. Available from: https://www.hcp.ma/region-drda/Population-legale-des-regions-provinces-prefectures-municipalites-arrondissements-et-communes-du-royaume-d-apresles_a89.html.

68. Siddiqui A, Halder S, Chauhan P, Kumar P. COVID-19 Pandemic and City-Level Nitrogen Dioxide (NO2) Reduction for Urban Centres of India. J. Indian Soc. Remote Sens. 2020;48:999-1006.

69. Mesas-Carrascosa FJ, Porras FP, Triviño-Tarradas P, García-Ferrer A, Meroño-Larriva JE. Effect of lockdown measures on atmospheric nitrogen dioxide during SARS-CoV-2 in Spain. Remote Sens. 2020;12.

70. Pacheco H, Díaz-López S, Jarre E, Pacheco H, Méndez W, Zamora-Ledezma E. NO2 levels after the COVID-19 lockdown in Ecuador: A trade-off between environment and human health. Urban Clim. 2020;34:100674.

71. Alqasemi AS, Hereher ME, Kaplan G, Fadhil Al-Quraishi AM, Saibi H. Impact of COVID-19 lockdown upon the air quality and surface urban heat island intensity over the United Arab Emirates. Sci. Total Environ. 2020;767:144330.

72. Huang X, Ding A, Gao J, et al. Enhanced secondary pollution offset reduction of primary emissions during COVID-19 lockdown in China. Natl. Sci. Rev. 2021;8:137.

73. Wang P, Chen K, Zhu S, Wang P, Zhang H. Severe air pollution events not avoided by reduced anthropogenic activities during COVID-19 outbreak. Resour. Conserv. Recycl. 2020;158:104814.

74. Ding J, van der A RJ, Eskes HJ, et al. NOx Emissions Reduction and Rebound in China Due to the COVID-19 Crisis. Geophys. Res. Lett. 2020;47:1-9.
75. Martin RV, Jacob DJ, Chance K, Kurosu TP, Palmer PI, Evans MJ. Global inventory of nitrogen oxide emissions constrained by space-based observations of NO2 columns. J. Geophys. Res. Atmos. 2003;108:1-12.

76. Kroll JH, Heald CL, Cappa CD, et al. The complex chemical effects of COVID-19 shutdowns on air quality. Nat. Chem. 2020;12:777-779.

77. Schneider P, Van Der A RJ. A global single-sensor analysis of 2002-2011 tropospheric nitrogen dioxide trends observed from space. J. Geophys. Res. Atmos. 2012;117:1-17.

78. Krotkov NA, McLinden CA, Li C, et al. Aura OMI observations of regional SO2 and NO2 pollution changes from 2005 to 2015. Atmos. Chem. Phys. 2016;16:4605-4629.

79. Stein ML. Spatial variation of total column ozone on a global scale. Ann. Appl. Stat. 2007;1:191-210.

80. Chandra S, Varotsos CA. Recent trends of the total column ozone: Implications for the Mediterranean region. Int. J. Remote Sens. 1995;16:1765-1769.

81. Salawitch RJ, David W. Fahey, Michaela I. Hegglin, Laura A. McBride, Walter R. Tribett SJD. 20 questions and answers. Available at: https://ozone.unep.org/20-questions-and-answers.

82. Weber M, Dikty S, Burrows JP, et al. The Brewer-Dobson circulation and total ozone from seasonal to decadal time scales. Atmos. Chem. Phys. 2011;11:11221-11235.

83. Li K, Jacob DJ, Liao H, et al. Ozone pollution in the North China Plain spreading into the late-winter haze season. Proc. Natl. Acad. Sci. U.S.A. 2021;118:1-7.

84. Sbai SE, Mejjad N, Norelyaqine A, Bentayeb F. Air quality change during the COVID-19 pandemic lockdown over the Auvergne-Rhône-Alpes region, France. Air Qual. Atmos. Heal. 2021;14:617-628.

85. Croitoru L, Sarraf M. Estimating the Health Cost of Air Pollution: The Case of Morocco. J. Environ. Prot. (Irvine,. Calif). 2017;08: 1087-1099.

86. Achebak H, Petetin H, Quijal-Zamorano M, Bowdalo D, García-Pando CP, Ballester J. Reduction in air pollution and attributable mortality due to COVID-19 lockdown. Lancet Planet. Heal. 2020;4:e268. 